\title{
Prescription Modification by Pharmacists in a Hospital Setting: Are Ontario Pharmacists Ready?
}

\author{
Vincent Vuong, Ramola Bhojwani, Anjana Sengar, and Allan Mills
}

Can J Hosp Pharm. 2021;74(3):235-47

DOI: 10.4212/cjhp.v74i3.3151

\begin{abstract}
Background: Under Ontario's Public Hospitals Act, the scope of professional practice of hospital pharmacists is approved by each hospital's medical advisory committee. Some Ontario hospitals have adopted policies or medical directives related to prescription modification, allowing pharmacists to broadly adapt, discontinue, hold, or renew prescriptions as part of their clinical scope of practice.

Objectives: The primary objective of this study was to describe Ontario hospital pharmacists' perception of their readiness to independently modify prescriptions. The secondary objectives of this study were to gather opinions on the perceived benefits, drawbacks, facilitators, and barriers to prescription modification by pharmacists and to determine how various factors affect perceived readiness.
\end{abstract}

Methods: A confidential web-based survey with Likert-type quantitative questions and qualitative open-ended questions was distributed to 936 hospital pharmacists in Ontario between May and July 2019. Mean scores were calculated for the following constructs affecting prescription modification: self-efficacy, support from the practice environment, and support from interprofessional relationships. Independent $t$ tests were conducted to compare responses between subgroups of interest. The answers to open-ended questions were analyzed thematically.

Results: The survey had a $29 \%$ response rate $(n=271)$. The mean selfefficacy score was 5.2 out of 7 (standard deviation [SD] 1.0, Cronbach $\alpha=0.88$ ), equivalent to "quite sure". The mean score for support from the practice environment was 3.3 out of 5 (SD 0.4, Cronbach $\alpha$ $=0.75$ ), equivalent to "not a factor". The mean score for support from interprofessional relationships was 4.2 out of 5 (SD 0.1, Cronbach $\alpha=$ 0.80 ), equivalent to "weak support". Improved efficiency of care, timelier interventions to improve medication safety and efficacy, and improved interprofessional collaboration were cited as benefits of prescription modification by pharmacists. Potential for inappropriate decision-making and miscommunication were cited as concerns. Respondents in hospitals who were already performing prescription modification reported higher self-efficacy to modify prescriptions in clinical areas of both familiarity and unfamiliarity and greater support from prescribers.

Conclusions: A large proportion of respondents to a survey of Ontario hospital pharmacists expressed an encouraging level of readiness to independently modify prescriptions. Responses to open-ended questions in this study provided valuable insights to inform widespread adoption of this practice change.

Keywords: pharmacy, hospital, Ontario, prescription, modification, adaptation

\section{RÉSUMÉ}

Contexte : En vertu de la Loi sur les hôpitaux publics de l'Ontario, le comité consultatif de chaque hôpital approuve l'élargissement de la pratique professionnelle des pharmaciens d'hôpitaux. Certains hôpitaux de l'Ontario ont adopté des politiques ou des directives médicales concernant la modification de la prescription. Celles-ci autorisent les pharmaciens à adapter, cesser, suspendre ou renouveler largement les prescriptions dans le cadre de leur champ de pratique.

Objectifs : L'objectif principal de cette étude visait à décrire la perception des pharmaciens d'hôpitaux de l'Ontario de leur degré de préparation à modifier des prescriptions de manière indépendante. Les objectifs secondaires consistaient à recueillir les opinions sur les avantages, les inconvénients, les éléments de facilitation et les obstacles perçus par les pharmaciens au sujet de la modification de la prescription et de définir comment divers facteurs influençaient la perception de leur degré de préparation.

Méthodes : Entre mai et juillet 2019, 936 pharmaciens d'hôpitaux en Ontario ont reçu une enquête confidentielle menée sur Internet comportant des questions quantitatives de type Likert et des questions ouvertes qualitatives. Les scores médians ont été calculés pour les concepts suivants liés à la modification de la prescription : I'autoefficacité, le soutien de I'environnement de pratique et le soutien des relations interprofessionnelles. Des tests $t$ indépendants ont été menés pour comparer les réponses entre les sous-groupes sous-groupes qui intéressaient les auteurs. Les réponses aux questions ouvertes ont été analysées par thème.

Résultats : Le taux de réponses à l'enquête se montait à $29 \%(n=271)$. Le score moyen pour le thème "Autoefficacité » était de 5,2 sur 7 (écart type [ET] 1, Cronbach $\alpha=0,88$ ), ce qui équivaut à la réponse «Assez certain ». Le score moyen pour le thème «Soutien de l'environnement de pratique » était de 3,3 sur $5(E T 0,4$, Cronbach $\alpha=0,75)$, ce qui équivaut à la réponse " N'est pas un facteur ». Le score moyen pour le thème « Relations interprofessionnelles » était de 4,2 sur 5 (ET 0,1, Cronbach $\alpha=0,80$ ), ce qui équivaut à la réponse « Soutien faible ». Les pharmaciens ont cité l'amélioration de l'efficacité des soins, les interventions en temps opportun visant à améliorer l'innocuité et l'efficacité des médicaments ainsi que l'amélioration de la collaboration interprofessionnelle comme étant des avantages de la modification indépendante des prescriptions. Ils ont aussi indiqué que le risque de prise de décision inappropriée ainsi que la mauvaise communication constituaient pour eux un sujet de préoccupation. Les répondants qui pratiquaient déjà la modification de la prescription en milieu hospitalier ont indiqué un gain d'autoefficacité de la modification des prescriptions dans des domaines cliniques qui leur sont familiers ou non, ainsi qu'un plus grand soutien de la part des prescripteurs.

Conclusions : Une grande partie des répondants à une enquête menée auprès de pharmaciens d'hôpitaux de l'Ontario ont jugé que leur degré de préparation à la modification indépendante des ordonnances était prometteur. Les réponses aux questions ouvertes de cette étude fournissent des éclaircissements précieux sur l'adoption généralisée de ce changement de pratique.

Mots-clés : pharmacie, hôpital, Ontario, prescription, modification, adaptation 


\section{INTRODUCTION}

To improve the quality, accessibility, and sustainability of the Canadian health care system, pharmacists working in collaborative professional environments should practise to the full extent of their knowledge and expertise. ${ }^{1}$ Within the health care team, pharmacists possess a unique skill set and knowledge base related to the use of medications. In a large database study, hospital pharmacist activities such as formulary development, prescriber education, drug order review, and participation in patient care rounds were shown to reduce mortality rates. ${ }^{2}$ Randomized studies have demonstrated reductions in hospital visits, drug-related readmissions, length of hospital stay, and health care costs in association with interventions by hospital pharmacists. ${ }^{3,4}$ Pharmacists possess, at a minimum, a Bachelor of Pharmacy or Doctor of Pharmacy degree, and many pharmacists have undertaken postgraduate clinical training. Hospital pharmacists in Canada are trained to have the knowledge, skills, and judgment to make independent decisions related to drug therapy optimization, in collaboration with the patient and the care team.

While reviewing prescriptions, pharmacists regularly identify drug therapy problems, such as the wrong dose for a given indication or organ dysfunction, the wrong dosage form, the wrong drug regimen, or the wrong route of administration (Table 1). In addition, pharmacists often identify situations where discontinuing, holding, or renewing medications would be beneficial, such as duplication of therapy or medications with an inappropriate stop date. For a majority of hospitals in Ontario, current inpatient pharmacy practice involves the pharmacist contacting the prescriber to suggest a drug therapy change and documentation of any resulting telephone or verbal prescription in the patient's chart. This process can interrupt the workflow of both the pharmacist and the prescriber and could potentially lead to delay in optimal therapy for the patient.

In Ontario, with the passing of Bill 179,5,6 pharmacists are now permitted to adapt and renew prescriptions while adhering to the standards of practice of the National Association of Pharmacy Regulatory Authorities ${ }^{7}$ and the Ontario College of Pharmacists (OCP) Code of Ethics. ${ }^{8}$ However, under Ontario's Public Hospitals Act, the professional practice scope of hospital pharmacists, including prescription adaptation and renewal, must be approved by each hospital's medical advisory committee. A minority of Ontario hospitals currently have policies or medical directives that allow for general adaptation, discontinuation, holding, or renewal of medication orders by pharmacists,

TABLE 1. Examples of Prescription Modification by Pharmacists

Identified Drug-Related Problem

Renal impairment dosing

recommendations

Patient has difficulty swallowing

Product strength not available

Strength not specified

Incorrect directions

Dosage form alternative

Discontinue duplicate therapy

Discontinue vaccine upon clarification of vaccine history

Hold order

medication
Current Order

Enoxaparin $40 \mathrm{mg} \mathrm{SC}$ daily for DVT prophylaxis (estimated creatinine clearance $25 \mathrm{~mL} / \mathrm{min}$ )

Levofloxacin $750 \mathrm{mg}$ PO daily

$\times 5$ days for pneumonia

Phenytoin $300 \mathrm{mg}$ PO daily

Diltiazem CD 120 mg PO daily

Ciprofloxacin $400 \mathrm{mg}$ PO bid $\times 3$ days for UTI

Flovent 1 puff bid

Risedronate $150 \mathrm{mg}$ PO daily

Betamethasone $0.1 \%$ lotion

Patient has an order for enoxaparin, and new order for apixaban is received

Prescriber ordered PNEUMOVAX 23, despite patient already having received a recent dose in the community

Olanzapine $25 \mathrm{mg}$ PO daily

(pharmacist completed BPMH and determines dose to be $2.5 \mathrm{mg}$ PO daily)

Eye drops for glaucoma discovered on completing the BPMH, but not ordered
Medication Order Written by the Pharmacist

Change enoxaparin to $30 \mathrm{mg}$ SC daily for DVT prophylaxis

Change levofloxacin to $750 \mathrm{mg} \underline{\mathrm{IV}}$ daily $\times 5$ days for pneumonia

Phenytoin $150 \mathrm{mg} \mathrm{NG}$ bid

Diltiazem immediate-release $30 \mathrm{mg} \mathrm{NG}$ qid

Change ciprofloxacin to $500 \mathrm{mg} \mathrm{PO}$ bid $\times 3$ days for UTI

Flovent $\underline{250 \mathrm{mcg}} 1$ puff bid

Risedronate $150 \mathrm{mg}$ PO monthly

Betamethasone $0.1 \%$ cream

Discontinue enoxaparin

Discontinue PNEUMOVAX 23 (once confirmed with community prescriber that vaccine was previously administered)

Hold olanzapine $25 \mathrm{mg}$ PO daily

(RPh reviews with MD)

latanoprost $0.005 \%$ one drop in right eye daily at bedtime

$\mathrm{BPMH}=$ best possible medication history, $\mathrm{CD}=$ controlled delivery, $\mathrm{DVT}=$ deep vein thrombosis, $\mathrm{MD}=$ physician, $\mathrm{NG}=$ nasogastric tube, $\mathrm{RPh}=\mathrm{registered}$ pharmacist, UTI = urinary tract infection. 
without the approval and/or signature of the authorized prescriber, and that are not limited to specific drugs, drug classes, or indications. See Box 1 (glossary of terms) for the definition of prescription adaptation, as well as other terms used in this article.

Outside of Ontario, several Canadian provinces have already legislated independent pharmacist prescribing, including Alberta, where pharmacists with "additional prescribing authority" can prescribe medications within their level of professional competence. ${ }^{10}$ A literature search of MEDLINE, Embase, Scopus, and IPA databases identified numerous barriers preventing prescription modification by pharmacists from becoming routine practice in Ontario hospitals, including fear of liability, lack of confidence, stress, lack of employer support, and lack of physician acceptance. ${ }^{11-15}$ To date, an assessment of the readiness of Ontario hospital pharmacists to modify prescriptions in a hospital setting has not been conducted.

The primary objective of this study was to determine, by means of a provincial survey, the perception of readiness of hospital pharmacists in Ontario to independently modify prescriptions, from individual and organizational perspectives. For the purposes of this study, prescription modification by pharmacists includes adaptation, discontinuation, holding, or renewal of medication orders. Narcotics, controlled drugs, and targeted substances were excluded, because pharmacists in Ontario do not have the authority to modify prescriptions for these medications. A secondary objective of this study was to gather opinions about the perceived benefits, drawbacks, facilitators, and barriers to pharmacists performing prescription modification, to inform the creation or adoption of tools, training materials, technology, or changes in workflow to help improve uptake. Another secondary objective was to determine how various factors, such as years of practice, location of pharmacy education, highest pharmacy degree obtained, postgraduate residency training, or hospital size, affected pharmacists' perceived readiness to modify prescriptions in a hospital setting.

\section{METHODS}

\section{Study Design and Setting}

A confidential, self-administered web-based survey was made available for completion by hospital pharmacists in Ontario, Canada. The survey sample was based on a list of pharmacists, provided by the OCP, who reported practising in an accredited Ontario hospital pharmacy workplace and consented to sharing their contact information for research purposes. An email invitation to participate in the study, with a link to the online survey (using the SurveyMonkey platform), was sent to all pharmacists on this list. The initial study invitation was sent at the beginning of May 2019, with reminder emails sent at the 2-, 6-, and 10-week time points. The overall survey period was from May to July 2019. To encourage response to the survey, participants were given the opportunity to win one of two $\$ 50$ gift cards. From a total of 2550 hospital pharmacists practising in Ontario at the time of this study (according to OCP data), a sample size of 334 participants was calculated to be representative for purposes of a descriptive survey, with a confidence level of $95 \%$ and a margin of error of $5 \% .{ }^{16}$

Survey eligibility was limited to pharmacists in Part A of the Public Register maintained by the OCP, that is, pharmacists who were licensed in Ontario and currently practising at an accredited Ontario hospital pharmacy. ${ }^{9}$ Pharmacy interns and pharmacy students were excluded, because the study aimed to gather thoughts and experiences from practising pharmacists. Part B pharmacists were also excluded, because prescription modification would not be applicable to their practice settings. ${ }^{9}$ Additionally, the 4 authors of this manuscript were excluded from participation.

The study was approved by the Trillium Health Partners Research Ethics Board. All participants in this study provided written informed consent via the online survey tool.

\section{BOX 1: Glossary of Terms}

Prescription adaptation: Prescription adaptation involves altering the dose, dosage form, regimen, or route of administration (e.g., to address a patient's unique needs and circumstances). Adapting a prescription does not include therapeutic substitution, which involves changing a pre-existing prescription to a chemically different product that is considered to be therapeutically equivalent. ${ }^{5,6}$

Prescription renewal: Prescription renewal involves providing a patient with a prescription that repeats a prescription previously provided to that patient (e.g., for the purpose of continuity of care) ${ }^{5,6}$

Prescription modification: Prescription modification is an umbrella term encompassing prescription adaptation, as well as discontinuation, holding, or renewal of a prescription.

Part A pharmacista: Pharmacists registered in Part A in Ontario are those who provide patient care and have worked a minimum of 600 hours in patient care over the previous 3 years. Patient care includes providing pharmacy services to the public, such as compounding, dispensing, providing drug information and education, and monitoring and managing medication therapy. ${ }^{9}$

Part B pharmacist ${ }^{\mathrm{a}}$ : Pharmacists registered in Part B in Ontario are those who do not, and have declared that they will not, provide patient care. ${ }^{9}$

aThe educational and practice requirements for Part A and Part B of the Public Register (as maintained by the Ontario College of Pharmacists [OCP]) are specified by the OCP's Quality Assurance Committee. 


\section{Survey Questions}

To assess the readiness of Ontario hospital pharmacists to modify prescriptions, an ad hoc survey tool was designed with a mixture of quantitative Likert-type questions and qualitative open-ended questions. Existing instruments to assess readiness for change in a health care setting were either too narrow or too broad in scope, were not well suited to a health care context, or lacked reliability and validity testing. ${ }^{17}$ In their perspective article, Holt and others ${ }^{18}$ conceptualized readiness for change in health care practice as consisting of various psychological and structural factors at both individual and organizational levels. Psychological readiness describes the extent to which an individual or organization is cognitively and emotionally inclined to accept, embrace, and implement a change, whereas structural readiness describes the extent to which the circumstances surrounding an individual or organization enhance or inhibit the acceptance and implementation of change. Our survey tool aimed to measure several of these factors in relation to the adoption of prescription modification by pharmacists.

An existing survey instrument with evidence for reliability and validity was developed by Guirguis and others ${ }^{19}$ for the purpose of measuring factors that influence pharmacists' adoption of prescribing in Alberta, Canada. We contacted the authors of that survey instrument and obtained permission to adapt their survey instrument to address our primary objective. For our Likert-type questions, we adapted 3 of the 8 scales with strong evidence for reliability and validity from the survey instrument by Guirguis and others, ${ }^{19}$ including questions about self-efficacy, support from the practice environment, and support from interprofessional relationships (for the complete survey, see Appendix 1, available at https://www.cjhp-online.ca/index.php/cjhp/issue/view/ 205). We included additional qualitative open-ended questions to address one of our secondary objectives.

\section{Pilot Test}

Before the survey was launched, a pilot survey was conducted with 25 hospital pharmacists at Trillium Health Partners in Ontario, Canada, to test for face validity, comprehensibility, completeness, layout, and participant burden of the survey tool. Completion of the pilot survey did not preclude participation in the provincial survey. Median time to complete the pilot survey was 18 minutes. To reduce respondent burden, nonessential demographic questions were removed, and open-ended questions were made optional. The wording of ambiguous questions was simplified, and the order of questions was modified to facilitate survey completion. Because of issues in interpreting questions in the "support from practice environment" scale, the questions were modified to inquire about factors more specific to prescription modification, such as amount of pharmacy staffing, current workload, technology, physical environment, and employer's expectations.
All changes to the survey were approved by the Trillium Health Partners Research Ethics Board before launch of the provincial survey.

\section{Data Analysis}

The response rate was calculated by dividing the number of survey respondents by the number of eligible participants. Survey respondents had to complete all mandatory questions to be included in the study. Demographic and practice information about survey respondents was summarized and compared with similar information for the total population of Ontario hospital pharmacists, to indicate representativeness.

Each response to a quantitative Likert-type question was converted to a numeric value. Responses were plotted and examined for normal distributions. Descriptive statistics, including means, medians, and standard deviations, were reported as appropriate for each quantitative question. We calculated means from the Likert-type scale data, as it is reasonable to do so if the data follow a normal distribution, ${ }^{20}$ and we could still draw inferences from the data because the values on our scales were reasonably distributed. ${ }^{21}$ Our revised tool was not previously tested in Ontario for the purposes of our research question, so the internal consistency of each of the 3 constructs (self-efficacy, support from the practice environment, and support from interprofessional relationships) was recalculated using the Cronbach a coefficient, a measure of how closely correlated a set of questions are within a construct. An a value greater than 0.70 was considered to indicate adequate reliability. Assuming internal consistency, overall construct mean score and standard deviation were determined by pooling the mean scores and their standard deviations for all questions within each construct. Exploratory subgroup analyses were conducted by performing independent $t$ tests between subgroups on the mean scores of each quantitative question, with $p$ values less than 0.05 being considered statistically significant.

For qualitative open-ended questions, thematic analysis was performed using NVivo 12 (QSR International) and Excel (Microsoft Corporation). All individual responses for each question were reviewed and coded into major themes and subthemes. Irrelevant responses to each question were removed. Each question response was reviewed numerous times, and major themes and subthemes were refined and quantified as patterns emerged. Selected quotes were highlighted.

\section{RESULTS}

From a list of 947 pharmacists provided by the OCP, 11 pharmacists were deemed ineligible to participate, which left a total of 936 eligible participants (Figure 1). Of the 936 eligible participants, 271 (29.0\%) completed the survey. These 271 respondents represented $10.6 \%$ of the 2550 hospital 


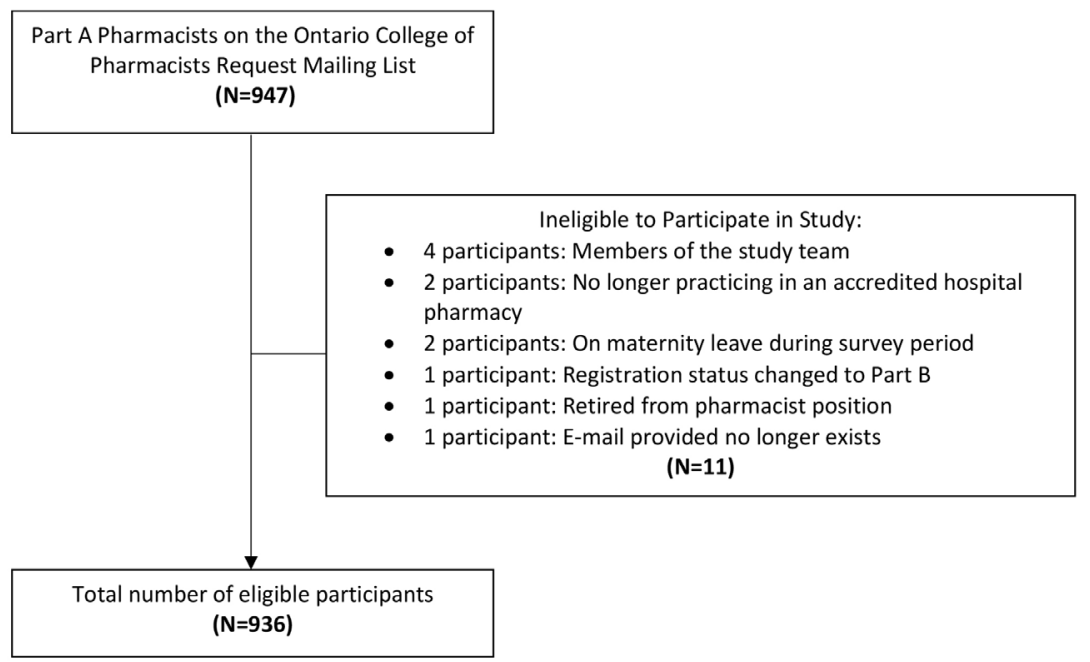

FIGURE 1. Flow chart of eligibility to participate in the survey.

pharmacists in Ontario. Relative to all hospital pharmacists in Ontario, the survey respondents were similar in distribution of gender, location of pharmacy education, and years of practice, with the caveat that the OCP Public Register reports data only for years licensed in Ontario and does not account for years of practice outside Ontario (Table 2). Of the 271 survey respondents, 56 (20.7\%) reported that their hospital workplace had an existing policy or medical directive to broadly modify prescriptions, whereas 215 respondents (79.3\%) reported that their workplaces did not have such policies or directives.

Among the 271 survey respondents, the mean score across the 7 questions for the self-efficacy scale was 5.2/7 (standard deviation $[\mathrm{SD}] 1.0$, Cronbach $\alpha=0.88$ ), indicating that respondents were "quite sure" that they could perform various aspects of prescription modification, including patient assessment, modification within clinical areas of both familiarity and nonfamiliarity, modification of both pre-existing and newly started therapies, documentation, and acceptance of responsibility for medication management (Table 3). The mean score across the 5 questions in the "support from practice environment" scale was 3.3/5 (SD 0.4, Cronbach $\alpha=0.75$ ), indicating that factors such as amount of pharmacy staffing, current patient load and/or other workload, technology, the physical practice environment, and the employer's expectations were "not a factor" in facilitating or hindering respondents' ability to modify orders. The mean score across the 2 questions in the "support from interprofessional relationships" scale was $4.2 / 5$ (SD 0.1, Cronbach $\alpha=0.80$ ), indicating that respondents felt that their relationships with prescribers, nurses, and other allied health professionals provided "weak support" in facilitating their ability to modify orders.

Subgroup analyses are reported in Appendix 2, Supplementary Tables S1-S7 (available at https://www.cjhp-online .ca/index.php/cjhp/issue/view/205). Respondents working in hospitals with an existing prescription modification policy or medical directive (relative to those in hospitals without such policies) reported higher self-efficacy to perform patient assessments (6.0/7 versus 5.4/7, $p<0.001$ ), to modify orders in clinical areas of unfamiliarity ( $3.6 / 7$ versus $3.1 / 7, p=0.039$ ), and to accept responsibility for medication management $(6.0 / 7$ versus. $5.6 / 7, p=0.019)$. Respondents at these hospitals also reported greater support from employers $(4.2 / 5$ versus $3.6 / 5, p<0.001)$, prescribers $(4.6 / 5$ versus $4.0 / 5, p<0.001)$, and nursing and allied health professionals (4.6/5 versus $4.3 / 5, p=0.007)$. Male respondents reported higher self-efficacy than female respondents to modify orders in clinical areas of unfamiliarity (3.6/7 versus $3.1 / 7$, $p=0.036)$. Respondents with 10 years or more of practice experience (relative to those with less than 10 years of practice experience) reported amount of pharmacy staffing $(2.8 / 5$ versus $3.4 / 5, p=0.001)$ and current patient load and/or workload (2.5/5 versus $2.9 / 5, p=0.025)$ as greater barriers to modifying prescriptions. Respondents with pharmacy residency training (relative to those without residency training) reported greater support from employers ( $4.0 / 5 \mathrm{ver}-$ sus $3.5 / 5, p=0.001$ ), prescribers $(4.4 / 5$ versus $4.0 / 5, p<0.001$ ), and nursing and allied health professionals $(4.5 / 5$ versus $4.3 / 5, p=0.037)$. Respondents working at hospitals with more than 500 beds (relative to those from hospitals with up to 500 beds) reported greater support from prescribers (4.4/5 versus $4.1 / 5, p=0.007$ ) but less support from pharmacy staffing $(2.7 / 5$ versus $3.2 / 5, p=0.012)$.

Major themes and subthemes generated from the qualitative questions are summarized in Table 4. Clear benefits of prescription modification by pharmacists to pharmacy practice as a whole include reducing workload, streamlining the distribution process, resolving drug therapy problems in a timelier manner, and increasing interprofessional collaboration. Nearly 1 in 10 responses linked the ability to independently modify prescriptions with 
increased job satisfaction, autonomy, and engagement. One respondent noted, "[Pharmacist prescription modification] helps me develop a stronger relationship with the patient care team as I can truly be the medication expert [who] can fix the patients' drug related problems." Listed benefits to patients included improving medication efficacy and safety through proactive pharmacist interventions, improving patient-centred care, and providing more opportunities for patient-pharmacist interaction.

Regarding potential problems, over a third of openended responses cited inappropriate decision-making because of factors such as improper or insufficient data collection or patient assessment; pharmacist limitations, such as gaps in therapeutic knowledge, lack of time, or lack of confidence; and pharmacy department limitations, such as inadequate staffing and logistical issues. One respondent expressed, "Pharmacists are not trained to assess patients and therefore I don't believe we should have the ability to largely modify prescriptions." Another third of responses cited miscommunication within the care team as a potential concern, including poor documentation of the care plan by the prescriber, poor communication of the change by the pharmacist to the care team, and confusion about responsibilities. A quarter of responses cited the potential for conflict among members of the care team or with the hospital organization. As one respondent noted, "Physicians think pharmacists will get too much power. In my hospital this has been an issue-they view us as a threat." Regarding personal limitations, less than $10 \%$ of responses reported personal barriers such as underdeveloped relationships with prescribers at their institution or personality traits such as avoidance of conflict or shyness. Regarding

\section{TABLE 2. Characteristics of Survey Respondents and Hospital Pharmacists in Ontario}

\begin{tabular}{|c|c|c|c|c|}
\hline \multirow{2}{*}{$\begin{array}{l}\text { Characteristic } \\
\text { Gender }\end{array}$} & \multicolumn{2}{|c|}{$\begin{array}{l}\text { No. }(\%) \text { of Respondents } \\
\qquad(n=271)\end{array}$} & \multicolumn{2}{|c|}{$\begin{array}{l}\text { No. (\%) of Hospital Pharmacists in Ontario } \\
\qquad(n=2550)\end{array}$} \\
\hline & & & & \\
\hline Female & 203 & $(74.9)$ & 1961 & $(76.9)$ \\
\hline Male & 67 & $(24.7)$ & 589 & $(23.1)$ \\
\hline Other & 1 & $(0.4)$ & 0 & \\
\hline \multicolumn{5}{|l|}{ Location of pharmacy education } \\
\hline Ontario & 197 & $(72.7)$ & 1776 & $(69.6)$ \\
\hline Elsewhere in Canada & 40 & $(14.8)$ & 389 & $(15.3)$ \\
\hline United States & 15 & $(5.5)$ & 170 & $(6.7)$ \\
\hline International, outside United States & 19 & $(7.0)$ & 215 & (8.4) \\
\hline \multicolumn{5}{|l|}{ Years of practice ${ }^{b}$} \\
\hline $0-4$ & 64 & $(23.6)$ & 504 & $(19.8)$ \\
\hline $5-9$ & 39 & $(14.4)$ & 528 & $(20.7)$ \\
\hline $10-14$ & 31 & $(11.4)$ & 425 & $(16.7)$ \\
\hline$\geq 15$ & 137 & $(50.6)$ & 1093 & $(42.9)$ \\
\hline Highest pharmacy degree obtained & & & Data & ilable \\
\hline BScPharm & 146 & $(53.9)$ & & \\
\hline PharmD, entry-level & 54 & $(19.9)$ & & \\
\hline PharmD, postgraduate & 53 & $(19.6)$ & & \\
\hline Other & 18 & $(6.6)$ & & \\
\hline Postgraduate training & & & Data & ilable \\
\hline Hospital pharmacy residency & 91 & $(33.6)$ & & \\
\hline No hospital pharmacy residency & 180 & $(66.4)$ & & \\
\hline Hospital size, by number of beds & & & Data & ilable \\
\hline$<50$ & 9 & (3.3) & & \\
\hline $50-200$ & 57 & $(21.0)$ & & \\
\hline $201-500$ & 146 & $(53.9)$ & & \\
\hline$>500$ & 59 & $(21.8)$ & & \\
\hline Existing prescription modification policy or medical directive & & & Data & ilable \\
\hline Policy & 46 & $(17.0)$ & & \\
\hline Medical directive & 10 & (3.7) & & \\
\hline None & 215 & $(79.3)$ & & \\
\hline
\end{tabular}

aData provided by the Ontario College of Pharmacists.

${ }^{b}$ For survey respondents, these data refer to years of practice in a hospital setting; for Ontario pharmacists, these data refer to years licensed to practice in Ontario. 
the consequences of clinical errors, respondents were most worried about harming the patient, followed by losing the trust of other health care professionals or patients, litigation, regulatory board consequences (e.g., licence revocation or suspension), and employment consequences such as loss of employment. Despite these potential consequences, roughly $15 \%$ of responses did not indicate any concerns with prescription modification by pharmacists, including the following statements from respondents: "[As pharmacists], we are professionals and need to be accountable for our decisions" and "If we are to expand our therapeutic involvement, we would naturally need to expand our liability."

Regarding needs for additional training, two-thirds of responses cited clinical training in specialty areas such as pediatrics, intensive care, or antimicrobial stewardship, as well as other broad topics including therapeutic drug monitoring, interpreting laboratory results and diagnostic tests/ imaging, approach to diagnosis and differentials, and basic

TABLE 3. Overall Survey Responses $(n=271)$

\begin{tabular}{|c|c|c|c|c|c|c|}
\hline \multirow[b]{2}{*}{ Survey Section and Questions ${ }^{a}$} & \multicolumn{3}{|c|}{ Data by Question } & \multicolumn{3}{|c|}{ Data for Construct } \\
\hline & Mean & Median & SD & Mean & SD & Cronbach $\alpha$ \\
\hline Self-efficacy — How sure are you that you could: & & & & $\begin{array}{l}5.2 \text { out of } 7 \\
\text { Quite sure }\end{array}$ & 1.0 & 0.88 \\
\hline $\begin{array}{l}\text { Question 1: Perform a patient assessment to modify any } \\
\text { medication order? }\end{array}$ & $\begin{array}{l}5.5 \text { out of } 7 \\
\text { Very sure }\end{array}$ & $\begin{array}{l}6.0 \text { out of } 7 \\
\text { Very sure }\end{array}$ & 1.3 & & & \\
\hline $\begin{array}{l}\text { Question 2: Modify any medication order in a clinical area } \\
\text { that you are familiar with? }\end{array}$ & $\begin{array}{l}5.8 \text { out of } 7 \\
\text { Very sure }\end{array}$ & $\begin{array}{l}6.0 \text { out of } 7 \\
\text { Very sure }\end{array}$ & 1.1 & & & \\
\hline $\begin{array}{l}\text { Question 3: Modify any medication order in a clinical area } \\
\text { that you are not familiar with? }\end{array}$ & $\begin{array}{l}3.2 \text { out of } 7 \\
\text { Somewhat sure }\end{array}$ & $\begin{array}{l}3.0 \text { out of } 7 \\
\text { Somewhat sure }\end{array}$ & 1.6 & & & \\
\hline $\begin{array}{l}\text { Question 4: Modify any medication order for patients starting } \\
\text { a new therapy in hospital? }\end{array}$ & $\begin{array}{l}4.5 \text { out of } 7 \\
\text { Quite sure }\end{array}$ & $\begin{array}{l}5.0 \text { out of } 7 \\
\text { Quite sure }\end{array}$ & 1.6 & & & \\
\hline $\begin{array}{l}\text { Question 5: Modify any medication order for patients } \\
\text { continuing a pre-existing therapy from home? }\end{array}$ & $\begin{array}{l}5.3 \text { out of } 7 \\
\text { Quite sure }\end{array}$ & $\begin{array}{l}6.0 \text { out of } 7 \\
\text { Very sure }\end{array}$ & 1.4 & & & \\
\hline $\begin{array}{l}\text { Question 6: Perform appropriate documentation for the } \\
\text { rationale of modifying a medication order? }\end{array}$ & $\begin{array}{l}6.0 \text { out of } 7 \\
\text { Very sure }\end{array}$ & $\begin{array}{l}6.0 \text { out of } 7 \\
\text { Very sure }\end{array}$ & 1.1 & & & \\
\hline $\begin{array}{l}\text { Question 7: Accept responsibility for medication } \\
\text { management? }\end{array}$ & $\begin{array}{l}5.7 \text { out of } 7 \\
\text { Very sure }\end{array}$ & $\begin{array}{l}6.0 \text { out of } 7 \\
\text { Very sure }\end{array}$ & 1.3 & & & \\
\hline $\begin{array}{l}\text { Support from practice environment - To what extent would the } f \\
\text { in your current practice location affect your ability to modify any } n\end{array}$ & $\begin{array}{l}\text { ollowing factors } \\
\text { nedication order? }\end{array}$ & & & $\begin{array}{l}3.3 \text { out of } 5 \\
\text { Not a factor }\end{array}$ & 0.4 & 0.75 \\
\hline Question 1: Amount of pharmacy staffing? & $\begin{array}{l}3.0 \text { out of } 5 \\
\text { Not a factor }\end{array}$ & $\begin{array}{l}3.0 \text { out of } 5 \\
\text { Not a factor }\end{array}$ & 1.4 & & & \\
\hline Question 2: Current patient load and/or other workload? & $\begin{array}{l}2.7 \text { out of } 5 \\
\text { Not a factor }\end{array}$ & $\begin{array}{l}2.0 \text { out of } 5 \\
\text { Weak barrier }\end{array}$ & 1.4 & & & \\
\hline Question 3: Technology? & $\begin{array}{l}3.6 \text { out of } 5 \\
\text { Weak support }\end{array}$ & $\begin{array}{l}4.0 \text { out of } 5 \\
\text { Weak support }\end{array}$ & 1.3 & & & \\
\hline Question 4: Physical practice environment? & $\begin{array}{l}3.4 \text { out of } 5 \\
\text { Not a factor }\end{array}$ & $\begin{array}{l}3.0 \text { out of } 5 \\
\text { Not a factor }\end{array}$ & 1.2 & & & \\
\hline Question 5: Employer's expectations? & $\begin{array}{l}3.7 \text { out of } 5 \\
\text { Weak support }\end{array}$ & $\begin{array}{l}4.0 \text { out of } 5 \\
\text { Weak support }\end{array}$ & 1.2 & & & \\
\hline $\begin{array}{l}\text { Support from interprofessional relationships - To what extent wo } \\
\text { following factors affect your ability to modify any medication orde }\end{array}$ & $\begin{array}{l}\text { ould the } \\
\text { er? }\end{array}$ & & & $\begin{array}{l}4.2 \text { out of } 5 \\
\text { Weak support }\end{array}$ & 0.1 & 0.80 \\
\hline Question 1: Relationship with prescribers? & $\begin{array}{l}4.2 \text { out of } 5 \\
\text { Weak support }\end{array}$ & $\begin{array}{l}4.0 \text { out of } 5 \\
\text { Weak support }\end{array}$ & 1.4 & & & \\
\hline $\begin{array}{l}\text { Question 2: Relationship with nursing and allied health } \\
\text { professionals? }\end{array}$ & $\begin{array}{c}4.3 \text { out of } 5 \\
\text { Weak support }\end{array}$ & $\begin{array}{l}5.0 \text { out of } 5 \\
\text { Weak support }\end{array}$ & 1.4 & & & \\
\hline
\end{tabular}

$\mathrm{SD}=$ standard deviation

a Complete details for each question are provided in Appendix 1 (available at https://www.cjhp-online.ca/index.php/cjhp/issue/view/205). 
physical assessments. One-third of responses to the same question supported having training to clearly outline the scope, restrictions, and expectations of any policy or medical directive, guidance on medical-legal implications, and appropriate documentation and monitoring procedures. Respondents felt that it was important to engage other health care professionals: "I think in a roll-out situation, communication to all stakeholders would be essential". For technology, over $80 \%$ of responses cited technological improvements that would facilitate access to all necessary patient information, including computerized physician order entry, electronic medical records, e-documentation, electronic medication administration records, and access to community data. For department-wide changes, nearly half of responses suggested active support and training from leadership, including ongoing continuous quality improvement and educational procedures, such as regular auditing or competency reassessment processes. A quarter of responses suggested optimization of pharmacy staff roles, including ensuring consistent pharmacist clinical coverage on consecutive days, minimizing technical responsibilities for pharmacists, and optimizing the scope of practice of pharmacy technicians. Suggested tools included creating case-based examples of different types of prescription modifications, having standardized templates for clinical assessment and documentation, and creating hospital-specific dosing guidelines.

\section{DISCUSSION}

Responses to the survey's quantitative questions provided valuable insights that Ontario hospital pharmacists feel they are individually ready to take on the practice change of prescription modification and do not feel that organizational factors such as their practice environment or interprofessional relationships present any barriers to performing this task. With the final sample size of 271 respondents, the quantitative results of our descriptive survey study were adequately representative of the population of hospital pharmacists in Ontario, with a confidence level of $95 \%$ and a margin of error of $6 \% .{ }^{22}$

Although our subgroup analyses were exploratory in nature, we can still draw inferences from the data, because parametric methods such as the $t$ test are robust enough to account for violations of assumptions. ${ }^{21}$ Higher scores for self-efficacy and support from interprofessional relationships for respondents working at institutions with existing

TABLE 4 (part 1 of 4). Emergent Themes from Qualitative Open-Ended Questions

\begin{tabular}{|c|c|c|}
\hline Open-Ended Question & $\begin{array}{l}\text { Major Themes } \\
\text { No. (\% Frequency) }\end{array}$ & Subthemes \\
\hline $\begin{array}{l}\text { A) How could pharmacist } \\
\text { prescription modification } \\
\text { benefit my practice? }\end{array}$ & $\begin{array}{l}\text { A1. Improve efficiency } \\
316(53.2 \%)\end{array}$ & $\begin{array}{l}\text { A1.1. Reduce workload, wastages, and cost } \\
\text { A1.2. Provide faster medication turnaround and streamlined distribution process } \\
\text { A1.3. Resolve drug therapy problems in a more timely manner } \\
\text { A1.4. Facilitate continuity of care }\end{array}$ \\
\hline \multirow[t]{3}{*}{594 responses } & $\begin{array}{l}\text { A2. Improve my ability to } \\
\text { provide better patient care } \\
148(24.9 \%)\end{array}$ & $\begin{array}{l}\text { A2.1. Improve medication efficacy and safety } \\
\text { A2.2. Provide patient-centred care } \\
\text { A2.3. Improve patient-pharmacist relationship }\end{array}$ \\
\hline & $\begin{array}{l}\text { A3. Promote full utilization of } \\
\text { pharmacists' scope of practice } \\
86(14.5 \%)\end{array}$ & $\begin{array}{l}\text { A3.1. Improve job satisfaction, engagement, and autonomy } \\
\text { A3.2. Increase ability to reinforce medication expertise } \\
\text { A3.3. Provide more opportunities for self-learning and professional advancement }\end{array}$ \\
\hline & $\begin{array}{l}\text { A4. Increase interprofessional } \\
\text { collaboration } \\
44(7.4 \%)\end{array}$ & $\begin{array}{l}\text { A4.1. Improve interprofessional relationships } \\
\text { A4.2. Share accountability and responsibility for patient care } \\
\text { A4.3. Provide opportunities for interprofessional teaching }\end{array}$ \\
\hline $\begin{array}{l}\text { B) How could pharmacist } \\
\text { prescription modification } \\
\text { benefit patients? }\end{array}$ & $\begin{array}{l}\text { B1. Improve patient outcomes } \\
447(92.2 \%)\end{array}$ & $\begin{array}{l}\text { B1.1. Improve medication efficacy and safety } \\
\text { B1.2. Reduce delay to appropriate drug therapy } \\
\text { B1.3. Facilitate continuity of care } \\
\text { B1.4. Provide patient-centred care }\end{array}$ \\
\hline \multirow[t]{3}{*}{485 responses } & & $\begin{array}{l}\text { B1.5. Reduce length of hospital stay } \\
\text { B1.6. Increase access to care } \\
\text { B1.7. Improve patient satisfaction and hospital experience } \\
\text { B1.8. Improve medication adherence }\end{array}$ \\
\hline & $\begin{array}{l}\text { B2. Increase interaction with } \\
\text { pharmacists } \\
30(6.2 \%)\end{array}$ & $\begin{array}{l}\text { B2.1. Increase opportunities for discussion with pharmacist and development of a } \\
\text { patient-pharmacist relationship } \\
\text { B2.2. Improve understanding of the hospital pharmacist's role }\end{array}$ \\
\hline & $\begin{array}{l}\text { B3. Financial savings } \\
8(1.6 \%)\end{array}$ & $\begin{array}{l}\text { B3.1. Pharmacist review of drug coverage options } \\
\text { B3.2. Pharmacist-initiated change to formulary alternative }\end{array}$ \\
\hline
\end{tabular}




\section{TABLE 4 (part 2 of 4). Emergent Themes from Qualitative Open-Ended Questions}

\section{Open-Ended Question}

C) What are some problems that could arise from pharmacist prescription modification?

461 responses

D) What consequences from clinical errors due to pharmacist prescription modification am I concerned about?

219 responses

\section{Major Themes}

No. (\% Frequency)

C1. Inappropriate prescription modification by pharmacist $161(34.9 \%)$

C2. Miscommunication within care team

$137(29.7 \%)$

C3. Potential conflict with members of the care team or hospital leadership $118(25.6 \%)$

C4. Potential for less verbal discussion with prescriber $17(3.7 \%)$

C5. Poor patient acceptance $15(3.3 \%)$

C6. Increase in pharmacist workload and responsibilities $7(1.5 \%)$

C7. Increase in wastage $6(1.3 \%)$

D1. Patient harm or medication error 67 (30.6\%)

D2. Loss of support, trust, or confidence from others $42(19.2 \%)$

D3. Litigation

$40(18.3 \%)$

D4. No concerns

$28(12.8 \%)$

D5. Regulatory board consequences $18(8.2 \%)$

D6. Liability insurance $11(5.0 \%)$

D7. Employment consequences $9(4.1 \%)$

D8. Personal stress $4(1.8 \%)$
Subthemes

C1.1. Incomplete or inaccurate data collection and/or patient assessment C1.2. Pharmacist limitations

C1.3. Pharmacy department limitations

C1.4. Lack of a double-check for pharmacists

C1.5. Conflict of interest

C2.1. Poor prescriber documentation of original rationale, care plan, and/or diagnosis

C2.2. Poor pharmacist communication of change to the care team

C2.3. Confusion with regard to responsibilities, accountability, and liability

C2.4. Prescriber's failure to note changes

C2.5. Confusion regarding discharge medications

C2.6. Logistical/technology errors

C3.1. Prescriber-pharmacist disagreement, conflict, or loss of trust after modification

C3.2. Disapproval of full pharmacist scope by prescribers or hospital leadership

C3.3. Conflict with nursing or other allied health

C4.1. Missed opportunities to educate prescribers

C4.2. Less opportunity to establish rapport, consensus

C5.1. Lack of patient-pharmacist communication regarding change

C5.2. Lack of trust in pharmacists

C6.1 Increase in pharmacist workload

C7.1. Duplication of work

C7.2. Excessive ordering of lab tests

D1.1. Adverse drug reaction, toxicity, or death

D1.2. Deterioration of current condition

D2.1. From other health care professionals

D2.2. From patients or the general public

D2.3. From the hospital organization

D3.1. To individual pharmacist

D3.2. To hospital organization

D4.1. Pharmacists should practise at their own comfort level/competence

D4.2. Pharmacists should recognize when a discussion with the prescriber is warranted

D4.3. Pharmacists should perform appropriate assessment, documentation, and follow-up

D4.4. Pharmacists must stay within the scope of the policy/medical directive

D5.1. Licence revocation/suspension

D5.2. Fine

D5.3. Patient filing a concern with regulatory college

D6.1. Uncertainty of insurance coverage for prescription modification activities D6.2. Increased insurance premiums

D7.1. Loss of employment

D7.2. Patient/family complaint to hospital employer

D7.3. Employer reprimand

D8.1. Loss of self-confidence

D8.2. Mental stress over decisions made 


\section{TABLE 4 (part 3 of 4). Emergent Themes from Qualitative Open-Ended Questions}

$\begin{array}{cc}\text { Major Themes } \\ \text { Open-Ended Question } & \text { No. (\% Frequency) }\end{array}$

\section{Subthemes}

E) What types of additional training would be beneficial to support my ability to modify orders?

224 responses

\section{E1. Additional clinical training} $146(65.2 \%)$

\section{(1)}

F) What are personal limitations in my ability to perform prescription modification?

186 responses
E2. Training specific to pharmacist prescription modification $78(34.8 \%)$

F1. Lack of knowledge, experience, or training $97(52.2 \%)$

$$
\begin{aligned}
& \text { F2. Lack of time } \\
& 46(24.7 \%)
\end{aligned}
$$

F3. Fear $13(7.0 \%)$

F4. Lack of confidence/comfort $12(6.5 \%)$

F5. Underdeveloped relationship with interprofessional team $12(6.5 \%)$

F6. Personality traits or personal beliefs $4(2.2 \%)$

F7. Ability to receive feedback $1(0.5 \%)$

F8. Physical barriers $1(0.5 \%)$
E1.1. Specialty clinical areas or medication-related topics

E1.2. Interpreting diagnostic imaging, tests, and lab values

E1.3. Diagnosis and differentials

E1.4. Physical assessment

E1.5. Continuing education

E1.6. Residency training

E2.1. Scope, restrictions, and expectations of policy/medical directive

E2.2. Appropriate documentation

E2.3. Pharmacotherapy work-up process and clinical judgment

E2.4. Effective communication strategies

E2.5. Medical-legal implications

E2.6. Practice cases

E2.7. Policy dissemination to other health care professionals

E2.8. Appropriate monitoring/follow-up

E2.9. Pharmacist peer mentorship

E2.10. Feedback from other stakeholder groups

E2.11. Certification/recertification processes

F1.1. Lack of knowledge in particular therapeutic areas or medications

F1.2. Missing information for patient data gathering

F1.3. Lack of experience/training with clinical assessment and/or decision-making

F1.4. Lack of training in diagnosis and differentials

F1.5. Not keeping up with new evidence and guidelines

F1.6. Lack of retail and outpatient pharmacy experience

F2.1. Competing priorities and workload

F2.2. Inefficiencies in practice

F3.1. Fear of making an incomplete or inaccurate assessment

F3.2. Fear of liability

F3.3. Fear of damage to relationships or loss of trust

F4.1. Lack of confidence with clinical decision-making

F4.2. Lack of comfort in areas outside of my expertise

F5.1. Lack of relationship with prescribers

F5.2. Lack of relationship with nursing and allied health

F6.1. Avoidance of conflict

F6.2. Shyness

F6.3. Disagreement with pharmacists' clinical scope of practice

F7.1. Difficulty with handling complaints

F8.1. Limited by dispensary role; unable to physically review paper chart or interview patient 


\section{Open-Ended Question \\ No. (\% Frequency)}

G1. Improvements to the hospital information system $95(70.4 \%)$

the could improve

my ability to perform

prescription adaptation?

135 responses

H) What are some department-wide changes that could better prepare my pharmacy department to perform prescription adaptation?

196 responses

\section{G2. Access to health information in the community $18(13.3 \%)$}

G3. Access to computers $11(8.1 \%)$

G4. Access to particular clinical resources (e.g., UpToDate, Dynamed, Lexicomp, Micromedex, Sanford Guide) $8(5.9 \%)$

G5. Improvements in peer-topeer communication 3 (2.2\%)

H1. Provide support and continuing education $91(46.4 \%)$

H2. Increase efficiency of
pharmacist clinical roles
$31(15.8 \%)$

H3. Optimize pharmacist staffing

$22(11.2 \%)$

H4. Develop support tools $21(10.7 \%)$

H5. Increase technology investment 15 (7.7\%)

H6. Reduce pharmacist dispensary roles $8(4.1 \%)$

H7. Develop prerequisite or alternative policies/medical directives

$4(2.0 \%)$

H8. Increase physical workspace $4(2.0 \%)$

\section{Subthemes}

G1.1. Electronic medical records, charting, medication administration records, and bedside data

G1.2. Computerized physician order entry

G1.3. Electronic pharmacist documentation

G1.4. Integration of separate software programs

G1.5. Electronic generation of clinical lists, reports, and drug queries

G1.6. Off-site access

G1.7. Electronic medication reconciliation

G2.1. Community labs, diagnostic imaging, or tests

G2.2. Community pharmacy data (e.g., filled prescriptions, insurance coverage)

G2.3. Provincial/national centralized EMR system

G3.1. Personal laptop/tablet computer

G3.2. Additional workstations/workspace

G4.1. On-site access

G4.2. Mobile applications

G5.1. Improved methods to reach physicians

H1.1. Development of a standardized policy/medical directive

H1.2. Involvement of interprofessional staff

H1.3. Pharmacist training sessions

H1.4. Support from pharmacy management and hospital leadership

H1.5. Continuous quality improvement

H1.6. Pharmacist peer education and mentorship

H1.7. Improve onboarding for new hires

H2.1. Allocate more time to clinical activities

H2.2. Optimize scope of pharmacy technicians

H2.3. Standardize documentation processes

H2.4. Consistency of clinical coverage for consecutive days

H2.5. More program-focus instead of dispensary-focus

H3.1. Increase pharmacy staffing

H3.2. Rational scheduling/cross-coverage

H3.3. Preference for hiring experienced staff

H4.1. Case-based examples or guidelines on different types of prescription modifications H4.2. Documentation templates

H4.3. Clinical guidelines (e.g., renal dosing, antibiotic dosing)

H4.4. Clinical assessment/care plan templates

See subthemes for question $\mathrm{G}$

H6.1. Minimize or remove order entry or other technical responsibilities

H6.2. Dedicated dispensary versus clinical pharmacists, rather than a mixed clinical and dispensary role

H7.1. Prescription modification limited to particular drugs or drug classes (e.g., vancomycin or aminoglycosides)

H7.2. Pharmacist prescribing (e.g., for minor ailments, nicotine replacement therapy)

H7.3. Harmonization of existing policies/medical directives

H8.1. Additional workspace within dispensary or on floors

$E M R=$ electronic medical records. 
prescription modification policies or medical directives suggests a positive reception for this practice change. The fact that respondents with 10 years or more of experience reported pharmacy staffing and patient load as greater barriers than did newer pharmacists may reflect the increasing clinical responsibilities of hospital pharmacists and the increasing strain of patient volumes on the Canadian health care system. Higher scores from residency-trained respondents regarding support from employers and other health care professionals could be due to factors ranging from greater comfort with working alongside the interprofessional team to feeling more valued and supported by their employers as a result of their specialized training, as well as differences in the collaborative practice environment of respondents. Compared with smaller hospitals, facilities with more than 500 beds can be subject to higher patient loads, but may have higher numbers of medical learners and residency-trained pharmacists, who could foster interprofessional collaboration.

The qualitative responses from our survey highlighted many benefits of prescription modification and identified potential limitations that pharmacists might experience. Word clouds, based on word frequency within the responses, were created to form snapshots of these perceived benefits and limitations (Figures 2 and 3). To minimize potential problems with this practice change, it is imperative that pharmacists always practise within their own comfort level and competence, putting the patient's best interests at the core of each intervention. Pharmacists can prevent miscommunication by ensuring that appropriate verbal communication is provided to care team members within a reasonable time frame after interventions are performed.

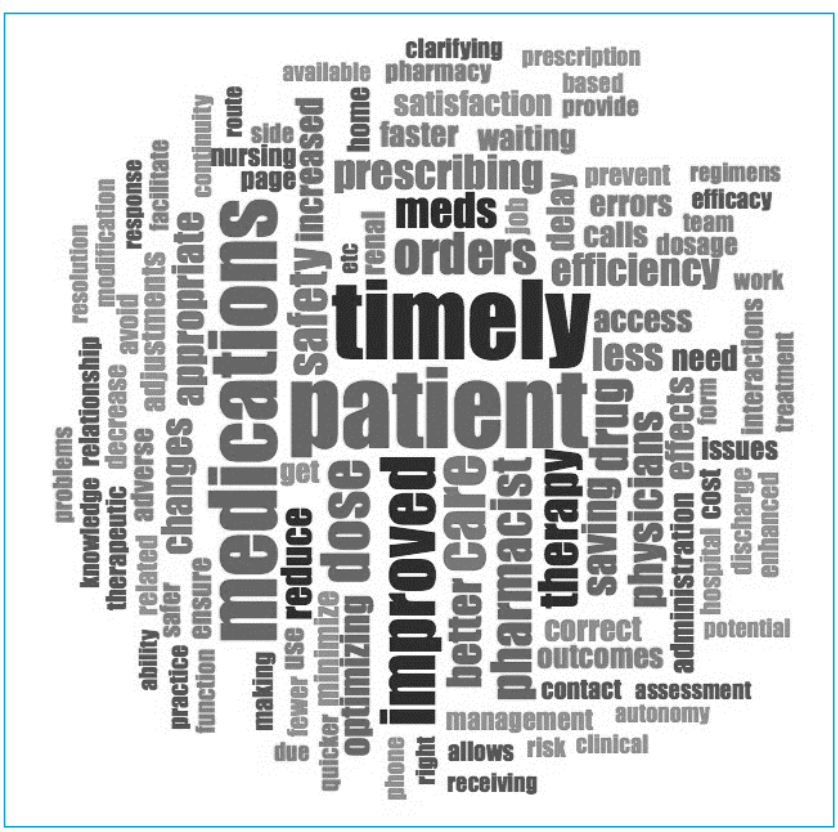

FIGURE 2. Word cloud representing the benefits of prescription modification by pharmacists, as perceived by survey respondents.
When applicable, written standardized documentation should always be provided. If pharmacists are unsure of the patient's status and/or the prescriber's intent, the prescriber should be contacted for clarification. If hospital pharmacy departments wish to pursue prescription modification by pharmacists, a methodical process to gather input from the pharmacy team, physician leaders, and other interprofessional staff is highly recommended. The roll-out plan should include communication and dissemination to all affected stakeholders. Offering training sessions catered to the needs and concerns of the pharmacist group and putting structures in place to maintain continuous quality improvement of the practice change are suggested.

A major limitation of this study was its reliance on self-reported data to provide insights into pharmacists' perceptions of their own readiness and how other health care professionals and stakeholders may view them. Future studies could gather input from nonpharmacy stakeholders. such as prescribers, nurses, other allied health professionals, and hospital administrators. There was a risk of sampling bias and nonresponse bias, as pharmacists who volunteered to be on the OCP mailing list and completed the survey might differ significantly from those who did not complete the survey. We attempted to minimize bias by inviting a large population (over one-third of all Ontario hospital pharmacists) and matching our survey sample to the overall population of Ontario hospital pharmacists on factors such as gender, location of pharmacy education, and years of practice. Finally, this study focused on pharmacy legislation in Ontario, and its results may not be applicable outside this province. Despite differences in pharmacy

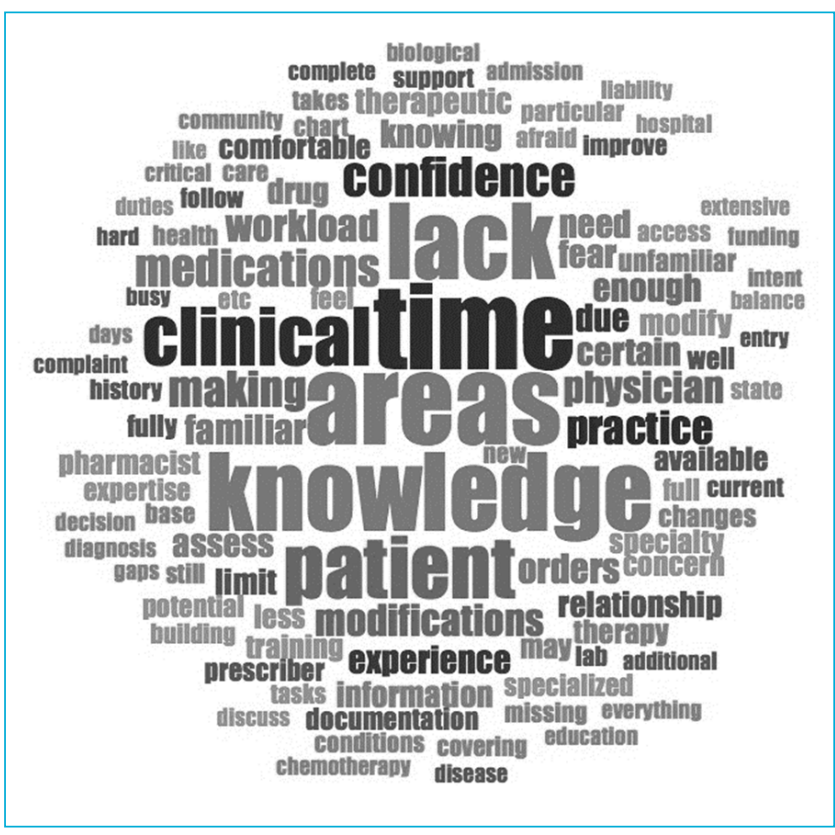

FIGURE 3. Word cloud representing limitations related to prescription modification by pharmacists, as perceived by survey respondents. 
practice from one province to another, it is hoped that the insights gathered from this study will be useful for preparing hospital pharmacy departments for future implementation or continuous quality improvement of similar changes in pharmacists' scope of practice.

\section{CONCLUSION}

A large proportion of Ontario hospital pharmacists expressed an encouraging level of readiness to perform prescription modification. Future directions include conducting prospective studies to characterize the impact of this practice change on measurable outcomes and to continue the pursuit of full pharmacist scope of practice across Canada and abroad.

\section{References}

1. Pharmacist Prescribing Task Force. Prescribing by pharmacists: information paper (2009). Can J Hosp Pharm. 2010;63(3):267-74.

2. Bond CA, Raehl CL. Clinical pharmacy services, pharmacy staffing, and hospital mortality rates. Pharmacotherapy. 2007;27(4):481-93.

3. Gillespie U, Alassaad A, Henrohn D, Garmo H, Hammarlund-Udenaes $\mathrm{M}$, Toss $\mathrm{H}$, et al. A comprehensive pharmacist intervention to reduce morbidity in patients 80 years or older: a randomized controlled trial. Arch Intern Med. 2009;169(9):894-900.

4. Hohl CM, Partovi N, Ghement I, Wickham ME, McGrail K, Reddekopp LN, et al. Impact of early in-hospital medication review by clinical pharmacists on health services utilization. PLoS One. 2017;12(2):e0170495.

5. Regulated Health Professions Statute Law Amendment Act, 2009, S.O. 2009, c. 26 - Bill 179.

6. Ontario Regulation 202/94: General (2016). Under Pharmacy Act, 1991, S.O. 1991, c. 36.

7. Model standards of practice for Canadian pharmacists. National Association of Pharmacy Regulatory Authorities; 2009 Mar.

8. Code of ethics. Ontario College of Pharmacists; 2015 [cited 2020 Mar 30]. Available from: https://www.ocpinfo.com/library/council/ download/CodeofEthics2015.pdf

9. Part A \& Part B register. Ontario College of Pharmacists; 2020 [cited 2020 Mar 30]. Available from: http://www.ocpinfo.com/registration/ register-pharmacist/two-part-register/

10. Pharmacists' expanded scope of practice. Canadian Pharmacists Association; 2018 [cited 2020 Mar 30]. Available from: https://www .pharmacists.ca/pharmacy-in-canada/scope-of-practice-canada/

11. Jorgenson D, Lamb D, MacKinnon NJ. Practice change challenges and priorities: a national survey of practising pharmacists. Can Pharm J. 2011;144(3):125-31.

12. Kondro W. Canada's doctors assail pharmacist prescribing. CMAJ. 2007;177(6):558.
13. Child D. Hospital nurses' perceptions of pharmacist prescribing. $\mathrm{Br} J$ Nurs. 2001;10:48-54.

14. Foong EAL, Grindrod KA, Houle SKD. Will I lose my license for that? A closer look at Canadian disciplinary hearings and what it means for pharmacists' practice to full scope. Can Pharm J. 2018;151(5):332-44.

15. Rosenthal M, Austin Z, Tsuyuki RT. Are pharmacists the ultimate barrier to pharmacy practice change? Can Pharm J. 2010;143(1):37-42.

16. Sample size calculator. SurveyMonkey; 2020 [cited 2020 Mar 30]. Available from: https://www.surveymonkey.com/mp/sample-size-calculator/

17. Gagnon MP, Attieh R, Ghandour el K, Légaré F, Ouimet M, Estabrooks $\mathrm{CA}$, et al. A systematic review of instruments to assess organizational readiness for knowledge translation in health care. PLoS One. 2014; 9(12):e114338.

18. Holt DT, Helfrich CD, Hall CG, Weiner BJ. Are you ready? How health professionals can comprehensively conceptualize readiness for change. J Gen Intern Med. 2010;25(Suppl 1):50-5.

19. Guirguis LM, Hughes CA, Makowsky MJ, Sadowski CA, Schindel TJ, Yuksel N, et al. Development and validation of a survey instrument to measure factors that influence pharmacist adoption of prescribing in Alberta, Canada. Pharm Pract (Granada). 2018;16(1):1068.

20. Sullivan GM, Artino AR Jr. Analyzing and interpreting data from likerttype scales. J Grad Med Educ. 2013;5(4):541-2.

21. Norman G. Likert scales, levels of measurement and the "laws" of statistics. Adv Health Sci Educ. 2010;15(5):625-32.

22. Margin of error calculator. SurveyMonkey; 2020 [cited 2020 Mar 30]. Available from: https://www.surveymonkey.com/mp/margin-of-error -calculator/

Vincent Vuong, BScPhm, PharmD, is with Trillium Health Partners, Mississauga, Ontario.

Ramola Bhojwani, BScPhm, PharmD, is with Trillium Health Partners, Mississauga, Ontario.

Anjana Sengar, BScPhm, PharmD, is with Trillium Health Partners, Mississauga, Ontario.

Allan Mills, BScPhm, PharmD, is with Trillium Health Partners, Mississauga, Ontario.

Competing interests: None declared.

Address correspondence to:

Dr Vincent Vuong

Trillium Health Partners

100 Queensway W

Mississauga ON L5B $1 \mathrm{~B} 8$

email: v5vuong@gmail.com

Funding: Funding for this project was provided by the Pharmacy Department at Trillium Health Partners.

Acknowledgements: The authors acknowledge Walter Wodchis and Judith Versloot, of the Trillium Health Partners Institute for Better Health, for providing survey methodology expertise. 